\title{
Dietary Sterol
}

National Cancer Institute

\section{Source}

National Cancer Institute. Dietary Sterol. NCI Thesaurus. Code C68342.

Any substance found in the diet, comprising a cholestane skeleton with a hydroxyl group at the position C-3. They occur naturally in plants, animals and fungi. 